\title{
9
}

\section{EFFECTIVE WAYS TO PREPARE FOR DEEPER LEARNING OF HISTORY}

\author{
Keita Shinogaya
}

\section{Summary}

Deeper learning of history, such as understanding causal relationships between relevant events, was promoted in junior high school students by assigning them a task to undertake preparatory learning for the following classroom lesson. In two experimental studies, it was revealed that interventions, such as asking students to read their textbook to generate questions about the causes of historical events and to find answers to those questions during preparation, enhanced scores in a subsequent test that directly asked about the causes of each historical event. This chapter describes how effective preparation to promote deeper learning can be facilitated in school students.

\section{Brief introduction: Importance of preparation for the next classroom lesson}

When we study school subjects, it is necessary to memorize each important fact and to deeply understand and construct a higher-order knowledge network. To achieve this kind of deeper learning in the classroom, homework plays an important role. Previous studies have shown that students' homework completion positively relates to their achievement (Cooper, 1989, 2001). However, researchers have pointed out that the effect of giving homework to students is not consistent (e.g, Flunger, Trautwein, Nagengast, Lüdtke, Niggli, \& Schnyder, 2015; Núñez, Suárez, Rosário, Vallejo, Cerezo, \& Valle, 2015), which means that we need to consider more carefully the kinds of, and ways of, administering homework in determining its effectiveness. According to Lee and Pruitt (1979), there are several types of homework depending on its purpose: practice (practicing the material that students have learned in class), preparation (preparing for the next 
lesson), extension (transferring prior knowledge to new situations), and creative (integrating several competencies in a research project). In regards to these types of homework, this chapter focuses on preparation, which is to learn the contents of an upcoming class beforehand, and is arguably necessary for deeper learning in class.

Assigning students the task of undertaking preparatory learning is also important for cultivating self-regulated learners. Learning skills to undertake preparation and deepen one's own learning is necessary in social and everyday life even after school. For example, self-regulated learners who are already in the workforce read handouts beforehand, generate questions, and maximize the effects of learning when they partake in seminars within the company. It is difficult to acquire learning skills like these without training. Schunk and Zimmerman (1997) proposed that the basis of academic skills shifts from social sources to the self through four stages: 1) observational, 2) imitative, 3) self-controlled, and 4) self-regulated. As part of this process, especially from the imitative stage to the self-controlled stage, students must have the opportunity to practice studying by themselves. Therefore, preparing for the next class can be effective for enhancing students' self-regulated learning skills and deepening their understanding of classroom lessons.

Despite its importance, however, preparation has not been examined adequately in learning research (Bang, 2012; Epstein \& Van Voorhis, 2001). In regards to this point, theories about meaningful learning are suggestive about the effect of preparation (Ausubel, 1968; Novak, 2002). In these theories, it is said that we can understand new information deeply when we connect it to our prior knowledge. In other words, to have prior knowledge for upcoming information is necessary for deeper learning. Research studies about advanced organizers have shown that reading a brief text about the learning materials beforehand could enhance retention of the contents (Ausubel, 1960). After Ausubel's research, many studies about advanced organizers were conducted in the 1980s. These studies revealed that if students gained knowledge about the contents of upcoming material beforehand, deeper learning, such as an understanding of the relationships between each fact or other piece of information, could be achieved (e.g., Bromage \& Mayer, 1986; Mayer, 1983; Mayer \& Bromage, 1980).

These findings provide useful suggestions when we consider the effect of preparatory learning for an upcoming class in which teachers use direct instruction. Of course they can be applied to learning various school subjects, but this chapter focuses especially on history learning because the effects of preparation can be considered most apt for the educational goals of this subject. In history learning at school, each historical fact (e.g., "Soon after World War I started, Japan decided to join in it") is stated, but its possible causes (e.g., "why Japan joined in it") are not usually explained in textbooks. And understanding causal relationships among facts is set as a goal of this subject. Thus, history teachers might explain "why a historical event happened," "why a person (or a country) behaved in a particular way," and so on, during classroom instruction. With this 
condition, deeper learning, such as understanding causal relationships among historical facts, can be achieved more efficaciously if students have already read the textbook beforehand.

\section{Individual differences in the effect of preparation}

Individual differences have to be considered with regard to the effect of preparation if school teachers are to ask their students to prepare for the next class. As mentioned above, findings of previous research studies on advanced organizers revealed the effect of preparation, but they have not adequately examined individual differences. If there are some students who cannot benefit from preparation (for reasons such as those described below), it is potentially useless to ask them to undertake preparatory learning because they could end up spending considerable amounts of time on an activity that would have no positive effect on their learning and achievement.

In this regard, learners' beliefs about learning are considered a factor that can cause individual differences in the effect of preparation. Beliefs about learning are what learners believe to be effective learning methods (Uesaka, Seo, \& Ichikawa, 2009). For example, Ueki (2002) asked Japanese high school students what they believed to be important for enhancing achievement and found three factors in beliefs about learning. The three factors were "strategy use" (e.g., students with high grades are those who use effective strategies), "amount of exercise" (e.g., there is no way other than spending a lot of time studying to enhance my grades), and "environment" (e.g., if I learn in an upper-level class, I can improve my grades).

Uesaka et al. (2009) reviewed previous studies that focused on beliefs about learning and developed a new questionnaire for assessing all kinds of learningrelated beliefs. In the questionnaire, they used two main categories of factors: cognitive beliefs and non-cognitive beliefs. Cognitive beliefs are beliefs that place importance on constructing knowledge and information processing. They contain subscales, such as meaningful learning (e.g., "I try to figure out relationships among different areas of knowledge") and thinking processes (e.g., "I try to find another way to solve the problem even after finding the answer"). Non-cognitive beliefs are beliefs that do not focus on constructing knowledge networks and information processing. They include subscales, such as rote memorizing (e.g., "If I remember perfectly, I can say that I understand") and outward results (e.g., "The process does not matter to me as long as my answer is correct").

\section{Description of the strategy}

As noted above, preparatory learning can be effective for promoting deeper learning in classroom instruction. If students undertake preparation and obtain prior knowledge about each fact, they can later learn more deeply. In other 
words, they would be able to better understand the reasons why those facts are true (e.g., "why Japan joined in World War I") during classroom instruction. In learning history, they would be able to better understand causal relationships between historical events when they read the textbook beforehand.

However, as mentioned earlier, there might be individual differences in the effect of preparatory learning. According to previous studies, non-cognitive learners are said to learn with shallow processing (e.g., Ueki, 2002; Uesaka et al., 2009). Especially the effect of preparation might not become apparent for learners who do not place importance on meaningful learning, but rather on rote memorization in learning. One way of circumventing this potential problem would be to direct learners' attention to causal relationships among historical facts in classroom instruction to enhance the effect of preparation.

In this regard, it might be effective to assign students to generate questions that ask about causal relationships during the preparatory task. It is important for students to have questions about the reason for each fact so that they perceive that solving questions is their goal in the next classroom lesson. In more concrete terms, this means they should not only read the textbook but also (1) generate questions that ask about the causes of each fact, and (2) come up with answers to those questions. These would likely be effective strategies for deepening students' learning during class. More concrete procedures for how this can be implemented are described below.

\section{Preparation}

1. Reading a textbook: to begin with, students read a textbook and gather knowledge about the contents of an upcoming classroom lesson. If teachers will deal with the content of two pages in the textbook, students need to read those two pages ahead of the classroom lesson. Using the textbook, students can usually only read brief explanations about each fact. For example, in history, explanations about what happened there (e.g., the Austrian crown prince and his wife were killed in Sarajevo) and who carried out such actions (e.g., a young Serbian) are provided in the textbook, with very limited or no analyses of causality and relationships. Learners can get these kinds of factual knowledge in advance during preparation.

2. Making questions: the explanations provided in the textbook are usually very simple, so learners often cannot understand sufficiently why the historical events happened. In history learning, to sufficiently understand "why a person carried out such action" and "why the incident happened there" during preparation is mostly impossible for the majority of learners.

However, if teachers ask them to generate such questions, it is difficult for leaners, especially elementary school students, to clarify the problem or point for which they require an explanation. In this case, teachers could 
guide or advice students to generate questions that start with "why." In cases where students are not yet capable of generating questions about what the teacher will focus on in the next classroom lesson, the teacher could generate the necessary questions and present those to students for them to consider during preparation.

3. Coming up with answers to the questions and setting goals for the next class: even if teachers ask students to generate questions that start with "why" or present the questions for students to use during preparation, it does not always lead to students learning more deeply. Especially, those who do not place importance on meaningful learning might generate questions that start with "why" without thinking deeply. Similarly, the questions presented by teachers may not deal with real issues or problems that students want addressed. Therefore students do not always recognize such questions during preparation as goals for the next class. In this case, teachers need to ask students to come up with possible answers to the questions. This activity makes it possible for students to realize that they cannot explain something well; therefore, they can recognize those questions as the problems to be solved in the next classroom lesson. If teachers inform students that the goal in a next class session would be to provide answers to those questions, students would be more likely to focus on relevant information relating to those questions during the ensuing classroom lesson.

Furthermore, assigning students to rate their confidence about their answers is also effective. For example, students could be asked to rate their confidence about their answers on a 5 -point Likert-type scale $(1=$ not confident at all, $2=$ not confident, 3 = difficult to decide either way, $4=$ a little confident, $5=$ very confident). If teachers inform students that the goal for a next class would be to increase their confidence ratings, students would be better able to appreciate the importance of clarifying the answers during that upcoming class.

\section{Classroom lesson}

After these activities in preparation, students participate in the corresponding classroom lesson. Teachers take time to explain to students the contents of the textbook, and this includes explaining the connections between each fact and the pertinent reasons that students need to understand about the content they are learning. In history learning, for example, teachers explain "why the historical event happened" and "why the person (or the country) behaved as such," and so on, in their classroom instruction. Preparation and classroom lessons like the above make it possible for students to connect each fact in the textbook and construct higher-order knowledge networks. It does not matter if teachers explain the relationships between the facts directly or make students discuss and come up with those explanations. The important thing is that learners can connect new input information in class to prior knowledge they got during preparation. 


\section{Evidence for the effectiveness of this preparation method}

\section{The effect of preparation and individual differences: Shinogaya (2008)}

In this study, a summer seminar for junior high school students was held, in which classroom instruction concerning history was provided for 86 8th-grade students. The purpose of this study was to examine the effect of preparation on deeper understanding of history in class, and to examine individual differences in the way this effect manifests in the context of educational practice. The seminar was held for 5 days at a university during summer vacation. The theme was World War I. This theme comprised new content for participants at that time (they had not studied it before). In this seminar, students were randomly assigned to one of three conditions: preparation class $(n=29)$, preparation and question-generation class $(n=29)$, and review class $(n=29)$. Students in the preparation class read the contents of the upcoming classroom lessons in the textbook for 5 minutes before the class. Students in the preparation and question-generation class were instructed not only to read the textbook before the class but also to generate questions that asked about the causes of historical events in the textbook. In this class, they were asked to generate questions that start with "why" (e.g., "Why did Britain occupy India?," "Why did Japan join World War I?”). Students in the review class were asked to read the textbook for 5 minutes after classroom instruction. (To control for variations in quantity and quality of preparation the students might undertake, they were instead asked to undertake the preparation/ review tasks in class, rather than at home.)

The students' beliefs about learning were measured with an adapted version of the questionnaire mentioned earlier (i.e., the Uesaka et al., 2009, questionnaire). Meaningful learning belief was gauged with the use of four items (e.g., "In history, it is important to understand relationships between the facts being learned"). Students were instructed to respond to these items on a 5-point Likert-type scale $(1=$ not at all true of me, $2=$ not very true of me, $3=$ difficult to decide either way, $4=$ a little true of me, $5=$ very true of $m e$ ). Their mean scores in the four items were calculated and used in the statistical analysis that was subsequently conducted.

In this study, students received classroom lessons for 4 days with variations in the preparation or review activity they engaged in depending on the condition. The contents and styles of classroom instruction were the same in the three conditions, wherein the teacher taught and explained the causes of historical events described in the textbook. In explaining, the teacher used the blackboard and a world map. After four lessons, on the fifth day of the seminar, students took two tests. One test asked students to read some sentences with blanks and to supply the appropriate words to fill the blanks. The answers to this test (names of historical events, country, and persons) were all provided in the textbook. The other test was an essay test that asked students to explain the causes of historical events and the behaviors of the countries/person(s). The causes were provided 
only in the classroom lessons, so the two preparation conditions were expected to achieve higher scores than the review condition in this essay test.

The result of statistical analysis of the fill-in-the-blank test data revealed that the scores of the three groups did not differ, which suggests that they learned and retained the historical facts equally well. However, students in the preparation condition and the preparation and question-generation condition achieved higher scores in the essay test (that asked for the causes of historical events) compared to those in the review condition. In addition, this study checked students' notebooks for each classroom lesson and counted their spontaneous notetaking about the causes of historical events that were explained only in classroom instruction. The result of this analysis showed that the students in the preparation condition and the preparation and question-generation condition took notes on the causes of the historical events during classroom lessons. These results suggest that getting prior knowledge about each historical event beforehand can promote students paying attention to the causes of each event during classroom lessons and deepening of their understanding of history.

\section{Individual differences in the effect of preparation}

Shinogaya (2008) additionally examined individual differences in the effect of preparation in the research described above. As shown in Figure 9.1, in the essay test score, the effect of preparation was found in students with higher meaningful learning belief scores. However, it was not shown in students with lower meaningful learning belief scores. The same trend was also found in students' note taking. In this study, the number of notes that students had spontaneously written in their notebooks about the causes of historical events was counted. The analysis result revealed that students with higher meaningful learning belief

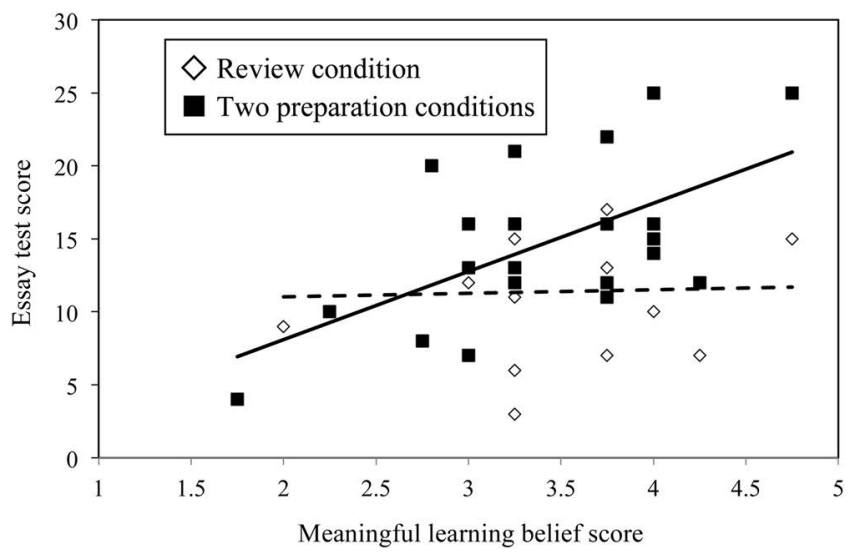

FIGURE 9.1 Effect of preparation in the essay test.

Notes. Solid line $=$ Trend of two preparation conditions; Dotted line $=$ Trend of review condition. 


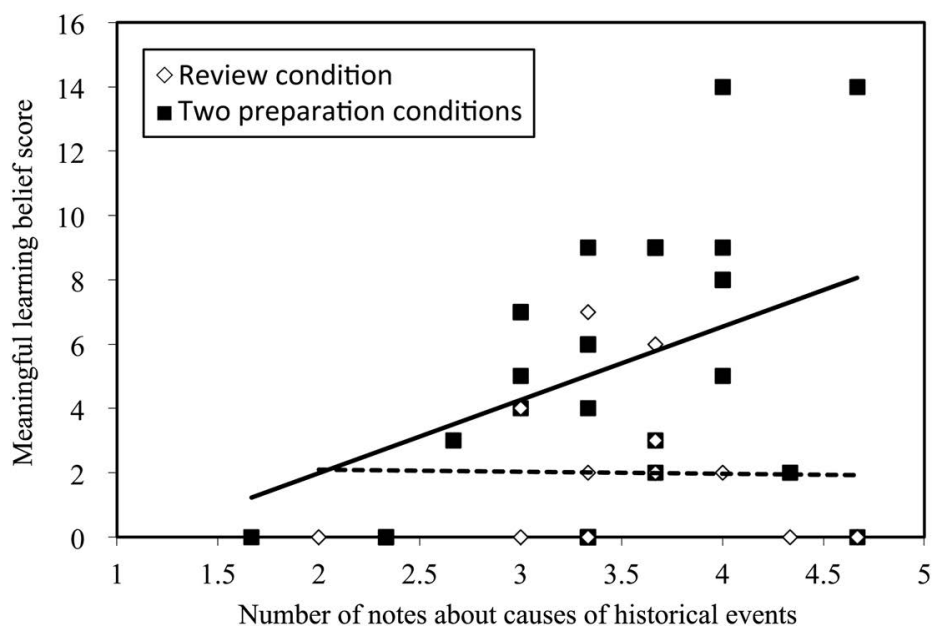

FIGURE 9.2 Effect of preparation in note taking.

Notes. Solid line $=$ Trend of two preparation conditions; Dotted line $=$ Trend of review condition.

scores spontaneously took more notes about the causes of historical events when they undertook preparation (Figure 9.2). In contrast, this effect of preparation was not found in students with lower meaningful learning belief scores.

\section{Directive preparation to deepen learning in classroom lessons: Shinogaya (2011)}

Shinogaya (2008) showed the effect of preparation on student achievement and how individual differences in learning beliefs can influence that effect. As a next step, the manner with which to direct students' attention to the causes of each fact being learned, and to promote deeper understanding, needed to be developed. In this regard, Shinogaya (2011) developed and evaluated a preparation strategy that may be effective for students with low scores in meaningful learning beliefs. To control for the quality and quantity of questions that students use in preparation, the teacher in this study provided the questions for students to use. For example, the textbook being used explained that Japan joined World War I because of an alliance with the UK, and thus one of the questions the teacher provided sought the reason for why Japan decided to join World War I.

In this study, a 5-day instructional seminar for students was held during the summer vacation. The 53 students who participated were randomly assigned to one of two classes. One was a "controlled preparation class" $(n=26)$ and the other was a "directive preparation class" $(n=27)$. In the controlled preparation class, students read the textbook for the upcoming class and were provided with three questions that asked about the causes of historical events in the textbook. The questions were already printed on a preparation sheet and the students were told that to find the answers to those questions was the goal of classroom instruction. 
In the directive preparation class, the students likewise read the textbook and were provided with the same questions as the controlled preparation group. The questions and blanks for answers to them were printed on their preparation sheet. The students were asked to come up with answers to the questions during preparation. In addition, students were also asked to rate their confidence about each of their answers on a 5 -point Likert-type scale $(1=$ not confident at all, $2=$ not confident, $3=$ difficult to decide either way, $4=$ a little confident, $5=$ very confident $)$, and they were told that increasing their confidence ratings was the goal of classroom instruction. The time spent on preparation in both classes was the same at about 10 minutes (as in Shinogaya, 2008, the preparation activities were carried out during the class sessions in order to control for potential variations and other confounding factors).

The contents of the classroom lessons were the same as in Shinogaya (2008). Students were provided classroom instruction about World War I for four days and were administered two tests on the fifth day of the seminar. One test asked students to read some sentences with blanks in them and to fill in those blanks with appropriate words. The other test was an essay test that asked students to explain the causes of historical events and the behaviors of countries/person(s).

As shown in Figure 9.3, meaningful learning belief scores evidenced a significant positive relationship with the students' scores in the essay test in the controlled preparation class (see the dotted line). In contrast, such a significant relationship was not found in the directive preparation class (see the solid line). Although the solid line looks like a negative slope, it was not significant in the statistical analysis, which means that there were no differences in the essay test scores in the directive preparation class as a function of the students' learning

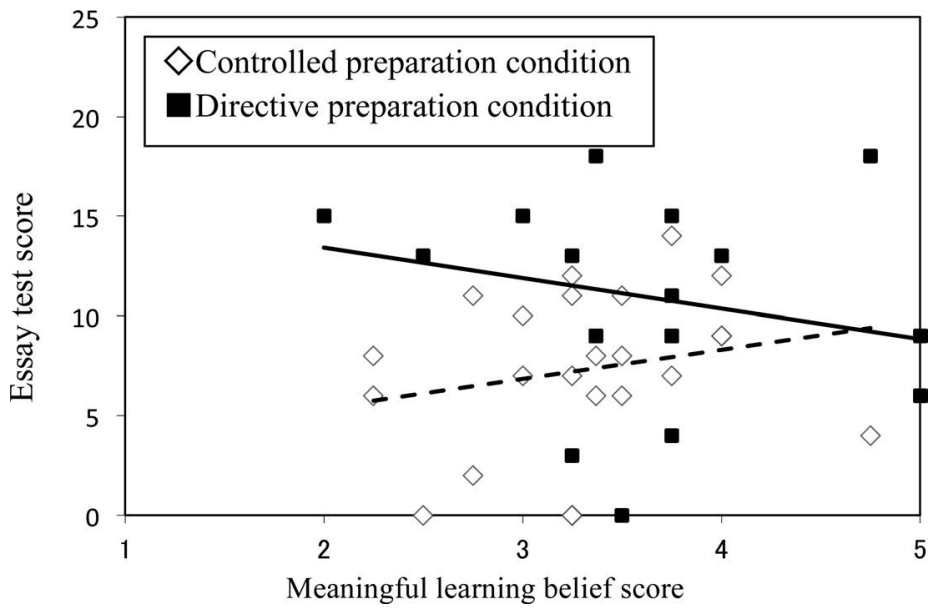

FIGURE 9.3 Effect of directive preparation and meaningful learning belief.

Notes. Solid line $=$ Trend of directive preparation condition; dotted line $=$ Trend of controlled preparation condition. 
belief scores. This result suggests that directive activities in preparation can guide the attention of students with low meaningful learning beliefs to the causes of historical events in class, thus promoting deeper learning. In other words, only reading the textbook and providing questions that ask for the causes of each historical event may not be sufficient in guiding students' attention to the important information, especially those students who have low meaningful learning beliefs. With directive activities like the ones included in the directive preparation class in this study, the negative effects of low meaningful learning beliefs can be alleviated - thus making preparation equally beneficial for all students.

\section{Discussion: What is an effective way to prepare for deeper learning?}

To undertake preparation and read the textbook beforehand make it possible for students to better understand the causes of and reasons for each item of knowledge set in the textbook. However, the beneficial effect of preparation can be moderated by students' beliefs about learning. Preparation is not always effective for students with a low meaningful learning belief. In addition, simply asking students to generate questions that ask the "why" of historical events is not always effective. According to King (1992, 1994), activities like these had positive effects on deepening students' learning. However, findings from the Shinogaya (2008) study revealed that meaningful learning belief affected the extent to which students could benefit from generating questions during preparation. The process of question generation has been described as comprising (1) noticing what is not understood, (2) comparing to prior knowledge, and (3) making questions (e.g., Van der Meij, 1990). Considering this process, only generating questions that start with "Why" does not provide comparison to prior knowledge. Thus, students with low meaningful learning beliefs do not recognize the questions to be their "own" questions (i.e., not related to what they really know or not know), and they do not subsequently pay attention to information connected to those questions they generated in preparation.

In this regard, Shinogaya (2011) showed that coming up with answers to the questions and rating their confidence level about those answers are effective strategies for directing students' attention to the important information they would later encounter in class. Previous studies about text understanding have shown that coming up with answers to pre-questions deepens understanding of the textbook content (e.g., Pressley, Tanenbaum, McDaniel, \& Wood, 1990; Thiede, Anderson, \& Therriault, 2003). The result of the Shinogaya (2011) study is consistent with these findings. In addition, rating confidence is also effective because not "understanding deeply," but "increasing the confidence rating" is easier for students to recognize as a goal for an upcoming classroom lesson. Previous studies suggest that a clear goal increases learners' self-efficacy, then enhances their motivation for the learning activity (Schunk, 1990, 2003). In Shinogaya (2011), the students' motivation for the upcoming class was not measured; however, 
the findings suggest that the rating activity enhanced their motivation and then deepened their learning during the classroom instruction.

According to the SOI (Selecting, Organizing, and Integrating) model (Mayer, 1996), learners select important information, organize it, and integrate new information with prior knowledge. Directing activities, such as coming up with answers to questions and rating confidence levels during preparation, may positively affect learners' selecting process. In addition, Ito (2004) pointed out that written information functions as an "outside memory resource"; thus, if answers are written on the preparation sheet, students can compare it to new information during the classroom lesson. Even if students select important information, it is difficult to integrate new information with their own answers without having written that information (i.e., the answers). Therefore, writing down answers to the questions also improves the integration process during the classroom lesson.

The findings of the two studies described in this chapter focused on history learning, but those findings can be adapted to suit other school subjects too. Undertaking preparation and reading the textbook beforehand deepens understanding during classroom lessons, irrespective of the school subject. For example, in mathematics learning, explanations about mathematical terms (e.g., a parallelogram) and how to calculate the answers to related problems (e.g., calculating the area of a parallelogram) are provided in textbooks, but usually not the underlying logic or rationale for those. And understanding "Why this formula is correct," "Why this procedure leads to an answer," and so on is needed in classroom lessons. In this case, deeper learning might be achieved if students read the textbook and gain knowledge about each formula and solving procedure beforehand. Individual differences in the effect of preparation may be observed. Then, to guide students' attention, setting questions that ask the "why" of each knowledge set, coming up with answers to them, and rating confidence about one's answers could be effective. At first, students may not be able to generate good questions by themselves. And even if teachers instruct them to ask questions that start with "Why," students with low meaningful learning beliefs may create questions without thinking deeply. If such a problem is encountered, teachers can provide questions for students to use during preparation. Coming up with answers to the questions and rating confidence levels about the answers could then direct students' attention to important information in class and deepen their understanding. Through such experiences, it is expected that students with low meaningful learning belief would perceive the value of asking "why" in their learning.

The most important thing is to consider the relationship between the contents of preparatory learning and of classroom instruction. In the two studies described in this chapter, the students read the textbook in preparation, and the teachers explained the causes of each set of knowledge described in the textbook during the classroom lessons provided. This relationship between preparation and classroom lesson is necessary for preparation to function as an advanced organizer for the next class. If teachers do not provide deeper and more meaningful content 
than what is already provided in the textbook, students may perceive classroom lessons as only repeating the contents of the textbook, thus their motivation for learning during class could be decreased by the prior preparation they have undertaken (i.e., if they consider what is being taught in class as something they already know from prior preparation). Many school teachers who disagree with preparation are anxious that students would not experience novelty and instead feel classroom instruction to be boring (e.g., Ichikawa, 2004). An effective way of preparing for an upcoming class depends on the content of classroom instruction: preparation and classroom lessons cannot be designed separately. Other previous studies have suggested that what and how teachers teach in classroom lessons can affect students' spontaneous strategy use in preparation, and the effect of preparation can be affected by teachers' teaching strategies in class (Shinogaya, 2014, 2017). For example, when teachers ask students about their own opinions in class, and they provide more detailed explanations in class than what is covered in the textbook, students' spontaneous preparation increases because students can perceive the necessity and value of preparation for the upcoming class.

\section{Limitations and directions for future research}

In the two studies described in this chapter, students conducted their preparation during the experimental class sessions rather than during homework. This was because control of individual differences in preparation (e.g., length of time spent on preparation, adherence to instructions given) was necessary to examine the effects of the intervention in each study. If we administer preparation as homework, it is likely that individual difference in preparation would occur. To avoid this, teaching concrete strategies such as those described in this chapter is one effective approach.

While the two studies about preparation described in this chapter examined effective ways of preparation for understanding instruction provided by teachers in classroom lessons, it is also necessary to examine the effect of preparation on learners' interactions in class. Getting prior knowledge might also affect cognitive processing of input information during learners' interactions. As mentioned above, learners process new input information with prior knowledge. Then, learners can better understand other leaners' opinions and explanations when they have undertaken preparation. In fact, research studies about cooperative learning have shown that learners with much prior knowledge can better integrate various pieces of information during interaction and deepen their learning (Gijlers \& de Jong, 2005; Schmidt, De Volder, De Grave, Moust, \& Patel, 1989). So far, many research studies about cooperative and collaborative learning have examined characteristics of effective learners' interactions (e.g., Okada \& Simon, 1997; Ootwijn, Boekaerts, \& Vedder, 2008). However, the effect of preparation on learners' interactions has not been examined adequately. Future research studies about preparation need to investigate the effects on, and effective ways of preparation for, learning through interaction. 
Recently, the importance of homework has been highlighted. However, many researchers and school teachers have largely neglected preparation as homework. Learning is not only attained with classroom instruction. Through the three learning phases of preparation, classroom lessons, and review, learning becomes deeper (cf. Shinogaya, 2012). Therefore, preparation is necessary for deeper learning in classroom lessons as learner's process new input information with their prior knowledge. In addition, to undertake preparatory learning is an important skill to keep learning effectively in everyday life. For students, it is important to connect what to learn in preparation and what to understand in classroom instruction to deepen their understanding and to develop their learning skills for the future.

\section{References}

Ausubel, D. P. (1960). The use of advance organizers in the learning and retention of meaningful verbal material. Journal of Educational Psychology, 51, 267-272.

Ausubel, D. P. (1968). Educational psychology: A cognitive view. New York: Holt, Rinehart and Winston.

Bang, H. (2012). Promising homework practices: Teachers' perspectives on making homework work for newcomer immigrant students. The High School Journal, 95, 3-31.

Bromage, B. K., \& Mayer, R. E. (1986). Quantitative and qualitative effects of repetition on learning from technical text. Journal of Educational Psychology, 78, 271-278.

Cooper, H. (1989). Synthesis of research on homework. Educational Leadership, 47, 85-91.

Cooper, H. (2001). The battle over homework: Common ground for administrators, teachers, and parents (2nd ed.). Thousand Oaks, CA: Sage.

Epstein, J. L., \& Van Voorhis, F. L. (2001). More than ten minutes: Teachers' roles in designing homework. Educational Psychologist, 36, 181-193.

Flunger, B., Trautwein, U., Nagengast, B., Lüdtke, O., Niggli, A., \& Schnyder, I. (2015). The Janus-faced nature of time spent on homework: Using latent profile analyses to predict academic achievement over a school year. Learning and Instruction, 39, 97-106.

Gijlers, H., \& de Jong, T. (2005). The relation between prior knowledge and students' collaborative discovery learning processes. Journal of Research in Science Teaching, 42, 264-282.

Ichikawa, S. (2004). Manabu iyoku to sukiru wo sodateru [Enhancing motivation and skills for learning]. Tokyo, Japan: Shogakukan.

Ito, M. (2004). Hikkisetsumei ga kouseitekigakusyu ni ataeru eikyou [Effect of writing explanation on constructive learning]. Tokyo, Japan: Kazama syobou.

King, A. (1992). Facilitating elaborative learning through guided student-generated questioning. Educational Psychologist, 27, 111-126.

King, A. (1994). Guided knowledge construction in the classroom: Effect of teacher children how to question and how to explain. American Educational Research Journal, 31, 338-368.

Lee, J., \& Pruitt, W. (1979). Homework assignments: Classroom games or teaching tools? The Clearing House, 53, 31-35.

Mayer, R. E. (1983). Can you repeat that? Qualitative effects of repetition and advance organizers on learning from science prose. Journal of Educational Psychology, 75, 40-49.

Mayer, R. E. (1996). Learning strategies for making sense out of expository text: The SOI model for guiding three cognitive processes in knowledge construction. Educational Psychology Review, 8, 357-371. 
Mayer, R. E., \& Bromage, B. K. (1980). Difference recall protocols for technical texts due to advance organizers. Journal of Educational Psychology, 72, 209-225.

Novak, J. D. (2002). Meaningful learning: The essential factor for conceptual change in limited or inappropriate propositional hierarchies leading to empowerment of learners. Science Education, 86, 548.

Núñez, J. C., Suárez, N., Rosário, P., Vallejo, G., Cerezo, R., \& Valle, A. (2015). Teachers' feedback on homework, homework-related behaviors, and academic achievement. The Journal of Educational Research, 108, 204-216.

Okada, T. \& Simon, H. A. (1997). Collaborative discovery in a scientific domain. Cognitive Science, 21, 109-146.

Ootwijn, M., Boekaerts, M., \& Vedder, P. (2008). The impact of teacher's role and pupils' ethnicity prior knowledge on pupils' performance and motivation to cooperate. Instructional Science, 36, 251-268.

Pressley, M., Tanenbaum, R., McDaniel, M. A., \& Wood, E. (1990). What happens when university students try to answer prequestions that accompany textbook material? Contemporary Educational Psychology, 15, 27-35.

Schmidt, H. G, De Volder, M. L, De Grave, W. S, Moust, J. H. C., \& Patel, V. L. (1989). Explanatory models in the processing of science text: The role of prior knowledge activation through small-group discussion. Journal of Educational Psychology, 81, 610-619.

Schunk, D. H. (1990). Goal setting and self-efficacy during self-regulated learning. Educational Psychologist, 25, 71-86.

Schunk, D. H. (2003). Self-efficacy for reading and writing: Influence of modeling, goal setting, and self-evaluation. Reading \& Writing Quarterly, 19, 159-172.

Schunk, D. H., \& Zimmerman, B. J. (1997). Social origins of self-regulatory competence. Educational Psychologist, 32, 195-208.

Shinogaya, K. (2008). Effects of preparation on learning: Interaction with beliefs about learning. Japanese Journal of Educational Psychology, 56, 256-267.

Shinogaya, K. (2011). Preparation for meaningful learning: Effects of method involving answering pre-questions and judging confidence in the answers. Japanese Journal of Educational Psychology, 59, 355-366.

Shinogaya, K. (2012). Learning strategies: A review from the perspective of the relation between learning phases. Japanese Journal of Educational Psychology, 60, 92-105.

Shinogaya, K. (2014). Students' strategies in preparation and lectures: Direct and moderating effects of teachers' teaching strategies. Japanese Journal of Educational Psychology, 62, 197-208.

Shinogaya, K. (2017). Motives, beliefs, and perceptions among learners affect preparatory learning strategies. Journal of Educational Research, 111, 612-619.

Thiede, K. W., Anderson, M. C. M., \& Therriault, D. (2003). Accuracy of metacognitive monitoring affects learning of texts. Journal of Educational Psychology, 95, 66-73.

Ueki, R. (2002). Structure of high-school students' beliefs about learning. Japanese Journal of Educational Psychology, 50, 301-310.

Uesaka, Y., Seo, M., \& Ichikawa, S. (2009). Students' cognitive and non-cognitive beliefs about learning as a factor in learning skills acquisition: Suggestions from cognitive counselling. In M. Sylvester (Ed.), Transformations: Proceedings of the 2008 Annual International Conference of the Association of Tertiary Learning Advisors of Aotearoa/New Zealand, (Vol. 4, pp. 89-100). Auckland, New Zealand: ATLAANZ.

Van der Meij, H. (1990). Question asking: To know that you do not know is not enough. Journal of Educational Psychology, 82, 505-512. 
$\Longrightarrow$ Taylor \& Francis Taylor \& Francis Group http://taylorandfrancis.com 